\title{
Fato ou Fake? Uma análise da desinformação frente à pandemia da Covid-19 no Brasil
}

\author{
Fact or Fake? An analysis of disinformation regarding the Covid-19 \\ pandemic in Brazil
}

Cláudia Pereira Galhardi (https://orcid.org/0000-0002-3047-9222) ${ }^{1}$

Neyson Pinheiro Freire (https://orcid.org/0000-0002-9038-9974) ${ }^{2}$

Maria Cecília de Souza Minayo (https://orcid.org/0000-0001-6187-9301) ${ }^{3}$

Maria Clara Marques Fagundes (https://orcid.org/0000-0003-4050-5655) ${ }^{4}$

${ }^{1}$ Escola Nacional de Saúde Pública Sérgio Arouca (ENSP), Fundação Oswaldo Cruz (Fiocruz). R. Leopoldo Bulhões 1480, Manguinhos. 21041-210 Rio de Janeiro RJ Brasil.

claudiagalhardi@usal.es

${ }^{2}$ Grupo de Estudos e

Pesquisa em Administração

dos Serviços de Saúde

e Gerenciamento de

Enfermagem, Universidade

Federal de São Paulo. São

Paulo SP Brasil.

${ }^{3}$ Departamento de Estudos

sobre Violência e Saúde

Jorge Careli, ENSP, Fiocruz.

Rio de Janeiro RJ Brasil.

${ }^{4}$ Grupo de Pesquisa

Maternidade, Saúde da

Mulher e da Criança,

Universidade Federal

Fluminense. Niterói RJ

Brasil.

\begin{abstract}
This paper aims to present an analysis of the most widespread fake news about the New Coronavirus (Sars-CoV-2) on social networks and how it can harm public health. This is a quantitative empirical study, based on the notifications received by the Eu Fiscalizo Brazilian application. The conclusions show that WhatsApp is the primary channel for sharing fake news, followed by Instagram and Facebook. We can conclude that the dissemination of malicious content related to Covid-19 contributes to the discrediting of science and global health institutions, and the solution to this problem is to increase the level of adequate information for Brazilian society.
\end{abstract}

Key words Fake news, Health, Pandemic, Posttruth, Covid-19
Resumo Este artigo tem como objetivo apresentar uma reflexão sobre as notícias falsas a respeito do novo coronavírus (Sars-CoV-2) mais disseminadas nas redes sociais e mostrar como podem causar prejuízos à saúde pública. Trata-se de um estudo empírico quantitativo, realizado a partir das notificações recebidas pelo aplicativo brasileiro Eu Fiscalizo. Os resultados da pesquisa mostram que o WhatsApp é o principal canal de compartilhamento de fake news, seguido do Instagram e do Facebook. Conclui-se que a disseminação de conteúdos falsos relacionados a Covid-19 contribui para o descrédito da ciência e das instituições globais de saúde. E que a solução para esse problema passa por aumentar o nível de informações adequadas para a sociedade brasileira.

Palavras-chave Fake news, Saúde, Pandemia, Pós-verdade, Covid-19 


\section{Introdução}

No final de dezembro de 2019, em Wuhan, China, foram identificados os primeiros casos de uma nova doença respiratória aguda, semelhante à pneumonia. $\mathrm{O}$ surto da doença espalhou-se velozmente para outros países, atingindo milhões de pessoas e levando a Organização Mundial da Saúde (OMS) a decretar a situação mundial como pandêmica no dia 11 de março de $2020^{1}$.

Diante da velocidade do contágio, com base na experiência da China e de outros países da Europa, a quarentena no Brasil foi estabelecida, gradualmente, seguindo recomendações da OMS e do Ministério da Saúde do Brasil. O Distrito Federal foi a primeira unidade da federação a estabelecer medidas de distanciamento social ampliado ${ }^{2}$.

Neste contexto, o distanciamento social foi recomendado como estratégia de controle da mobilidade da população, redução das atividades comerciais não essenciais, restrição de circulação de pessoas em eventos e transportes públicos, fechamento de escolas e universidades. Simultaneamente, autoridades governamentais estabeleceram o uso de máscaras e a higienização das mãos com álcool em gel, como medidas de prevenção, sempre seguindo recomendações das instituições globais de saúde e do Ministério da Saúde do Brasil ${ }^{3}$. Ações similares foram tomadas pelos estados, como foi o caso de São Paulo, em 16 de março, e do Rio de Janeiro, em 17 de março. No mesmo dia 17 de março, o Brasil registrou a primeira morte por Covid-19. Naquele momento, havia 301 casos da doença confirmados no país. Apesar das medidas preconizadas, a curva de casos e de óbitos seguiu aumentando de forma exponencial e assustadora ${ }^{4}$.

Por parte do Ministério da Saúde, as explicações públicas no começo da crise, explanadas diariamente pelo então ministro Luiz Henrique Mandetta e seus representantes, sublinhavam a necessidade de reforçar o isolamento, tendo como propósito frear a ascensão da curva de infectados e poupar os leitos de UTI dos hospitais, de modo a não saturar o Sistema Único de Saúde (SUS) $)^{5}$.

Como em várias partes do mundo, houve mudanças drásticas no cotidiano dos brasileiros, que foram acompanhadas por um crescimento vertiginoso de informações, nem sempre precisas, divulgadas todos os dias pelos meios de comunicação oficiais ou pelas redes sociais. Em consequência, uma crescente circulação de boatos acerca do contágio produziu uma segunda mazela pandêmica: a propagação de notícias falsas relacio- nadas à Covid-19 cujas fontes principais eram as redes sociais ${ }^{6}$. Esse movimento atingiu o mundo inteiro, a ponto de a Organização Mundial da Saúde (OMS) denominá-lo como "infodemia". O termo passou a ser incorporado no vocabulário atual como a disseminação em massa de notícias falsas e rumores que comprometem a credibilidade das explicações oficiais fundamentadas em respaldo científico". "Informações imprecisas sobre a Covid-19 estão se espalhando mais rapidamente do que o próprio vírus", disse Alexsandra Kuzmanovic, gerente de mídias sociais da OMS, em entrevista à rede de televisão $\mathrm{CNN}$, no início de março ${ }^{8}$. Desta forma, a história natural da doença e a especulação em torno da doença passaram a ser contadas em tempo real.

Sabe-se que a disseminação de informações falsas e a cultura da desinformação na área de saúde não é novidade. Em 2008, foram propagados boatos que ensinavam uma receita natural de proteção contra a febre amarela, nas redes sociais e no aplicativo de mensagem WhatsApp. Uma das teorias disseminadas era de que a doença seria uma farsa criada para vender vacinas. Havia ainda outras teorias, como a que dizia que a vacina paralisava o fígado, que mutações do vírus afetavam a eficácia da vacina e que o consumo de própolis poderia repelir o mosquito transmissor da doença. Neste período, observou-se uma reação popular muito diversa e confusa: houve os que correram em busca da vacina e os que foram vítimas dos que induziram à crença de que a imunização seria ineficaz e levaria à morte.

Por causa do surto da febre amarela em áreas urbanas, a meta do Ministério da Saúde era de vacinar $80 \%$ da população brasileira. No entanto, somente 55\% aderiram à campanha. Segundo a Organização Mundial da Saúde, as notícias falsas podem ter sido umas das causas que influenciaram para que a meta não fosse atingida ${ }^{9}$.

Para Henriques ${ }^{10}$, a saúde é um bom meio de cultura para boatos e rápida circulação de notícias. Segundo o pesquisador, a velocidade da disseminação de notícias falsas ocorre porque uma parcela da população não recebe informação adequada sobre os problemas de saúde que a afetam, pela falta de credibilidade nas autoridades sanitárias, e pela ansiedade que causam as notícias sobre doenças e epidemias. Na atualidade, quem acompanha noticiários e redes sociais observa que, em meio ao revolto mar de informações durante o surto da Covid-19, o fenômeno das fake news parece ter tomado uma proporção alarmante, viralizando notícias que aumentam o risco para a saúde da população ${ }^{11}$. 
Nesse contexto, este artigo tem como objetivo apresentar algumas fake news que têm circulado nas redes sociais durante a pandemia da Covid-19. Trata-se de um estudo empírico, realizado a partir da técnica de análise de conteúdo que estuda a circulação de notícias falsas propagadas durante a crise sanitária e notificadas por usuários do aplicativo Eu Fiscalizo.

\section{O fenômeno das fake news}

O termo fake news denomina a produção e propagação massiva de notícias falsas, com objetivo de distorcer fatos intencionalmente, de modo a atrair audiência, enganar, desinformar, induzir a erros, manipular a opinião pública, desprestigiar ou exaltar uma instituição ou uma pessoa, diante de um assunto específico, para obter vantagens econômicas e políticas ${ }^{12}$.

A expressão fake news popularizou-se mundialmente durante a cobertura jornalística da eleição presidencial de 2016, nos Estados Uni$\operatorname{dos}^{12}$. O termo foi usado na mídia pelo candidato a presidente dos Estados Unidos contra seus adversários, visando a desqualificar informações que favorecessem a candidatura deles ${ }^{13}$. Igualmente, no Reino Unido, o referendo que levou o país a sair da União Europeia (o Brexit) e a ingressar em uma grave crise política foi, em boa parte, arquitetado por mentiras de xenófobos e ativistas de direita ${ }^{14}$. A disseminação de notícias falsas alcançou também as eleições presidenciais no Brasil, quando a extrema direita supostamente conseguiu, graças ao poder viral das redes sociais, subverter a já combalida democracia nacional. $\mathrm{O}$ assunto, aqui no país, segue investigado em plena pandemia: a CPI das fake news disputa o noticiário com o novo coronavírus ${ }^{15}$.

Portanto é no contexto político que as notícias e falas falsas saíram do âmbito do jornalismo para serem usadas como tática de marketing eleitoral. O fenômeno de propagação de notícias falsas ganhou velocidade quase imediata, combinada com o alcance global ${ }^{13}$ da internet e das novas tecnologias, dos aparelhos celulares e das plataformas digitais que ampliaram a capacidade de comunicação do ser humano. Num disparo, uma notícia pode alcançar milhões de pessoas, sem que sua origem seja imediatamente identificada $^{16}$. No mesmo sentido, García ${ }^{17}$ cita a famosa frase de Goebbels, ministro da propaganda nazista, de que uma mentira repetida suficientemente torna-se uma verdade.

É a primeira vez que o mundo enfrenta uma pandemia nessa era digital de marketing político, era também chamada de pós-verdade. Esse termo, recentemente incluído no dicionário de Editora Oxford, define o conjunto de circunstâncias em que os fatos objetivos são menos influentes do que apelos à emoção e às crenças pessoais ${ }^{18,19}$ na formação da opinião pública. Para Figueira e Santos $^{20}$, a crescente influência das fake news sobre o universo offline e o embotamento da distinção entre a materialidade factual e o caráter analítico subjetivo das opiniões caracterizam a chamada pós-verdade, objeto de análise da área de comunicação, sobretudo a partir de 2016, como um dos efeitos das eleições presidenciais dos Estados Unidos.

Ou seja, um excesso de notícias falsas velozmente disseminadas revela uma inquietante perda de confiança em instituições antes conhecidas por apresentar e representar a verdade dos fatos: a imprensa, a ciência e as elites intelectuais em geral $^{21}$. Os dois termos, fake news e pós-verdade caminham juntos. No caso concreto da vivência social em tempos de Covid-19, acontece a combinação mais perigosa dos dois termos, pois as informações e orientações que contrariam o conhecimento científico disseminam o medo e até a prática de charlatanices, aumentando as chances de avanço da infecção e de mortes ${ }^{10}$.

\section{Material e método}

Neste estudo, aplicou-se a análise de conteúdo quantitativa sobre as notícias falsas produzidas e propagadas sobre a Covid-19, e notificadas pelo usuário do aplicativo Eu Fiscalizo. O aplicativo, idealizado com base em estudo de pós-doutoramento da pesquisadora Claudia Galhardi, na Escola Nacional de Saúde Pública (ENSP), foi supervisionado por Maria Cecília de Souza Minayo e apoiado pela Fundação de Amparo à Pesquisa do Estado do Rio de Janeiro (Faperj). Essa ferramenta viabiliza aos usuários que avaliem conteúdos veiculados nos meios de comunicação, entretenimento, plataformas digitais e, por meio dele, possam notificar conteúdos que julguem impróprios, exercendo, assim, sua cidadania pelo direito à comunicação e ao entretenimento de qualidade $^{22}$.

Lançado em uma sessão do senado federal no dia 10 de fevereiro, um mês antes de ser registrado o primeiro caso de Covid-19 no Brasil, a plataforma que recebia diversas denúncias sobre conteúdos impróprios para crianças e adolescentes na televisão aberta, por assinatura e serviço de streaming, cinema, jogos eletrônicos, espetáculos 
e publicidades, passou a receber $98 \%$ de notificações sobre notícias falsas e a Covid-19.

A partir dos dados desse aplicativo, apresentase a análise de conteúdo das fake news recolhidas no período de 17 de março a 10 de abril de 2020. Esse tipo de análise pode ser aplicado tanto do ponto de vista hermenêutico como quantitativo. Nesta investigação, utiliza-se a vertente quantitativa mais usada na área de comunicação para perceber o alcance dos fenômenos simbólicos, seu papel social, efeitos e repercussões ${ }^{23-26}$.

Na Figura 1, demonstra-se o desenho metodológico aqui proposto.

O período estabelecido para o estudo da notificação de fake news relacionadas ao novo coronavírus (Sars-CoVid-2) foi de 25 dias consecutivos. Para essa finalidade foram separadas, dentre as fake news denunciadas e armazenadas no aplicativo, as 154 relativas ao tema durante o tempo estipulado. Em seguida, foram codificadas e objeto de análise.

\section{Resultados e discussão}

Na Tabela 1 apresentam-se os dados sobre as principais fake news recebidas no aplicativo, na fase da pesquisa aqui analisada.
Como apresentado na Tabela 1, as notícias falsas recebidas entre 17 de março e 10 de abril revelam que $65 \%$ delas ensinavam métodos caseiros para prevenir o contágio da Covid-19; 20\% mostravam métodos caseiros para curar a doença; 5,7\% se referiam a golpes bancários; 5\% faziam menção a golpes sobre arrecadações para instituição de pesquisa; e 4,3\% diziam respeito ao uso do novo coronavírus como estratégia política.

A pesquisa apontou que $10,5 \%$ das notícias falsas foram publicadas no Instagram, $15,8 \%$ no Facebook e 73,7\% circularam via WhatsApp. Os resultados também mostram que $26,6 \%$ das fake news publicadas no Facebook atribuem à Fiocruz o papel de orientadora no que diz respeito à proteção contra o novo coronavírus. $\mathrm{O}$ estudo ressalta ainda que $71,4 \%$ das mensagens falsas circuladas pelo WhatsApp citam a Fundação como fonte de textos sobre a Covid-19 e com medidas de proteção e combate à doença. A Organização Mundial da Saúde (OMS) e o Fundo das Nações Unidas para a Infância (Unicef), juntas somam $2 \%$ das instituições citadas como fonte de informações sobre cuidados e medidas contra o novo coronavírus em mensagens de WhatsApp ${ }^{27}$.

Destacam-se, a seguir, as 10 principais fake news veiculadas sobre o coronavírus, denuncia-

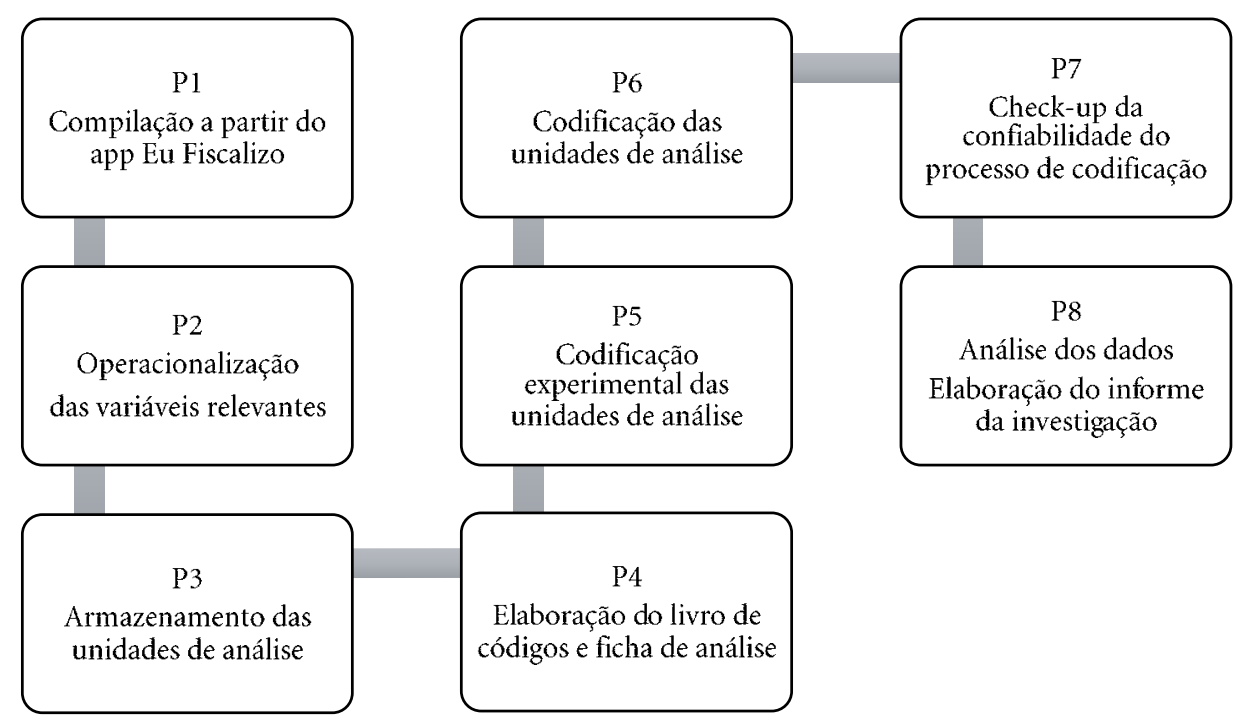

Figura 1. Desenho metodológico de análise. 
das por meio do Eu Fiscalizo, temas que foram comentados pela pneumologista e pesquisadora da ENSP, Margareth Dalcolmo:

1. Água fervida com alho serve como tratamento para o coronavirus. Segundo Margareth Dalcolmo, até o momento, não existe tratamento cientificamente comprovado com alho para o coronavírus. Estão sendo realizados testes com medicamentos e não com alimentos, mas ainda não há nada na ciência que valide a eficácia de nenhum deles.

2. O coronavírus é maior do que o normal, e, por isso, qualquer máscara impede sua entrada no organismo. $\mathrm{O}$ coronavírus não é um vírus maior do que o normal, de acordo com a pesquisadora. A máscara protege, sobretudo, em transportes coletivos, elevadores, entre outros lugares com maior número de pessoas.

3. Quando cai em uma superfície de metal, o vírus permanece vivo por 12 horas e, em tecido, por nove horas. Portanto, lavar a roupa ou colocá-la ao sol por duas horas elimina o vírus. $\mathrm{O}$ vírus permanece maior tempo em superfícies de plástico, não de metal. A pesquisadora destaca que a lavagem de roupa, com água e sabão é indicada para a eliminação do contágio. No entanto, a exposição ou não da roupa ao sol não interfere em sua eliminação.

4. $O$ vírus vive na mão por 10 minutos. Não há evidências científicas que comprovem o tempo em que o vírus permanece nas mãos, segundo Margareth. $\mathrm{O}$ indicado é fazer a lavagem adequada delas sempre que possível. E com água e sabão.

5. O vírus exposto a uma temperatura superior a 26 graus morre. Diz a pesquisadora, não existe um limite de temperatura à qual o vírus não resista.

6. Como o vírus não resiste à temperatura superior a 26 graus, a água exposta ao sol pode ser consumida sem qualquer perigo. Já que não existe limite de temperatura ao qual o vírus não resiste, não é indicado consumir água exposta ao sol.

7. O vírus se propaga no ar - Sim, mas por meio de gotículas ou em aerossol, provocados pela tosse, inclusive, em procedimentos médicos. Daí a razão de tantos profissionais de saúde terem sido contaminados, segundo ela.

8. Evitar comer gelados ou pratos frios. Pratos frios ou quentes não interferem na resistência do vírus, de acordo com a pesquisadora.

9. Gargarejar com água morna ou salgada evita que o vírus vá para os pulmões. Água morna ou salgada não evita que o vírus atinja os pulmões. Margareth esclarece que o comprometimento dos pulmões vai depender de características fisiológicas do indivíduo infectado.

10. Álcool em gel pode ser feito em casa com apenas dois ingredientes - Não é indicado que se produza álcool em gel em casa. O material de limpeza mais indicado na eliminação do coronavírus, segundo a pesquisadora, é qualquer detergente que se usa para lavar a louça ou água sanitária. Pode ser feito um material de limpeza caseiro, diluindo água sanitária na proporção de 1 litro para 3 litros de água. Isso serve também para limpar superfícies lisas, sobretudo as de plástico, onde o vírus pode permanecer mais tempo. A melhor maneira como padrão ouro de limpeza é ainda água e sabão. O álcool em gel sozinho não pode ser utilizado todo o tempo. As mãos precisam ser realmente lavadas, destaca a pesquisadora.

As notícias falsas disseminadas pelas plataformas digitais relacionadas ao SARS-CoV-2 podem influenciar o comportamento da população e colocar em risco a adesão do cidadão aos cuidados cientificamente comprovados. Os dados quantitativos desta investigação comprovam que a disseminação de falsas notícias sobre cura e prevenção, sem nenhum embasamento científico, são produzidas ou por ignorância ou com a intenção de desinformar e induzir o cidadão a cometer erros nas decisões pessoais e cuidados com sua saúde. Num cenário pandêmico, isso é ainda mais perigoso, pois pesquisas mostram que 110 milhões de brasileiros acreditam em notícias falsas sobre a Covid-1928.

Informação da mesma fonte indica que nove em cada 10 brasileiros entrevistados no país leram ou ouviram pelo menos uma informação falsa sobre a doença, e sete em cada 10 acreditaram em, ao menos, um conteúdo desinformativo sobre a pandemia ${ }^{29}$. Ou seja, o desconhecimento, a desinformação ou a má fé podem levar deter- 
minados indivíduos a contagiarem centenas de pessoas com o coronavírus, anulando os esforços de médicos e do poder público. É o que avalia a coordenadora de campanhas da Avaaz (organização não governamental de mobilização social), Laura Moraes ${ }^{29}$.

Os especialistas em comunicação são unânimes em afirmar que as declarações do presidente da república do Brasil têm contribuído para desinformar e confundir a população sobre os métodos de evitar a transmissão da doença. Logo após criticar a quarentena e o fechamento de escolas e comércio, em pronunciamento na noite de 24 de março, a plataforma de monitoramento digital Torabit identificou milhares de comentários de usuários nas mídias sociais em dúvida se deveriam ou não interromper a quarentena. "A confusão foi grande, porque a fala do presidente foi imediatamente condenada por várias entidades médicas e governadores. Muitas pessoas ficaram sem saber em quem deveriam acreditar", declarou a publicitária Stephanie Jorge, cofundadora da Torabit, em reportagem da revista Pesquisa Fapesp. De acordo com Stephanie, observou-se naqueles dias, uma explosão de notícias falsas relacionando o novo coronavírus com fatos políticos ${ }^{8}$.

Outro exemplo emblemático nesse período foi o aumento de intoxicação por beber produtos de limpeza na cidade de Nova York, após o presidente americano declarar que a ingestão de desinfetante combateria o novo coronavírus. É comprovado que o uso de desinfetante é eficaz para matar o vírus na desinfecção de residências, no entanto, o presidente dos Estados Unidos, na coletiva de imprensa diária na Casa Branca sobre a Covid-19, sugeriu ingestão de determinados produtos para o tratamento de pacientes infectados. Segundo reportagem do NY Daily News, nas 18 horas seguintes à declaração de Trump, $o$ número de novaiorquinos que recorreram às autoridades de saúde por intoxicações causadas por ingestão de água sanitária ou outros produtos de limpeza aumentou, quando comparado ao mesmo período de $2019^{30}$.

As fake news também são identificadas nas mensagens de determinadas pessoas com poder, com o intuito de propagar conteúdo não necessariamente falso, mas com objetivo de capitalizar política e economicamente ${ }^{31}$. Há ainda criminosos que se aproveitam do medo e do pânico da sociedade para disseminar links e se apropriar de dados sigilosos das vítimas ${ }^{32}$. Um golpe bancário foi notificado pelo aplicativo Eu fiscalizo. A mensagem de SMS solicitava que o cliente clicasse num link para atualizar seus dados e, caso não o fizesse, sua conta seria bloqueada (Figura 2). Segundo a agência Lupa, de março a junho de 2020, 65 fraudes foram desmentidas por plataformas de verificação de notícias falsas na América Latina, Espanha e Portugal ${ }^{33}$.

Outro veículo que possui informações que ajudam a explicar a situação nacional frente às fake news é a empresa global de cibersegurança Kaspersky, em parceria com a empresa de pesquisa CORPA, na América Latina. Segundo pesquisa desses órgãos, $62 \%$ dos brasileiros não sabem reconhecer se uma mensagem é falsa ou verdadei$\mathrm{ra}^{32}$.

Há ainda outro tipo golpe denunciado no $E u$ fiscalizo. Refere-se a um post produzido pelo Movimento Brasil Livre (MBL) para a arrecadação de doações. A publicação ressalta a indicação da Fundação Oswaldo Cruz (Fiocruz) como laboratório de referência para o combate à Covid-19 e estampa a foto do Castelo da Fundação, sede do Rio de Janeiro (Figura 3). A narrativa apresentada no post é verdadeira, no entanto, no rodapé da postagem, é indicado o site do MBL que direciona o usuário para a página de contribuições do Movimento. É certo que a Fiocruz lançou, no dia 2 de abril de 2020, uma campanha de arrecadação de verbas a serem destinadas ao enfrentamento do novo coronavírus. No entanto, a campanha, batizada como Unidos contra a Covid-19, recebe doações de pessoas físicas e jurídicas feitas diretamente na página da instituição $0^{34}$.

Foi também detectada pelo Eu Fiscalizo, outra mensagem compartilhada nas redes sociais que deslegitimava os dados oficiais apresentados pelo Portal da Transparência do Registro Civil acerca dos óbitos no estado do Ceará, por conta do novo coronavírus. De acordo com post recebido, os atestados de óbito por doenças respiratórias no Ceará, no período de 16 de março a 10 de maio de 2020 estariam sendo alterados para óbitos por Covid-19 (Figura 4). Segundo a checagem realizada pela agência Lupa, os dados do referido post estavam desatualizados e incluíam mortes não relacionadas com problemas respiratórios. No dia 11 de maio, os números verificados no Portal da Transparência do Registro Civil de 2019, mostravam 2.808 óbitos por doenças respiratórias contra 3.217, em 2020 - o que representava um aumento de aproximadamente 409 no Estado e acréscimo de $14,5 \%$ quando comparado ao registrado em $2019^{35}$.

O compartilhamento de notícias falsas tem $70 \%$ mais chances de viralizar do que as notícias verdadeiras, conclui um estudo conduzido por 
pesquisadores do Massachusetts Institute of Technology. De acordo com a pesquisa, cada postagem verdadeira alcança, em média mil pessoas, enquanto as falsas atingem de mil a $100 \mathrm{mil}^{36}$.

Em trabalho recente, publicado no periódico Trends in Cognitive Science, Jay Van Bavel ${ }^{37}$, professor de psicologia e ciência neural da Universidade de Nova York compartilhou o que descobriu sobre o processo que leva as pessoas a acreditarem em notícias falsas. Entre os pontos levantados, o professor destaca o chamado "viés de confirmação", que se traduz na tendência de muitos indivíduos buscarem informações que reafirmem suas próprias crenças, seja por meio de memórias seletivas e ou de leituras de fontes que estão ao seu lado. Por isso, esse pesquisador conclui que o ser humano tem uma tendência a abraçar e a compartilhar evidências que reforcem sua visão de mundo e de rejeitar tudo aquilo que a contradiz $z^{37}$.

Em entrevista à BBC News Brasil, o psiquiatra e diretor da Associação Brasileira de Psiquiatria, Cláudio Martins ${ }^{38}$, afirmou que pessoas que compartilham notícias falsas experimentam uma sensação de bem-estar semelhante às que usam

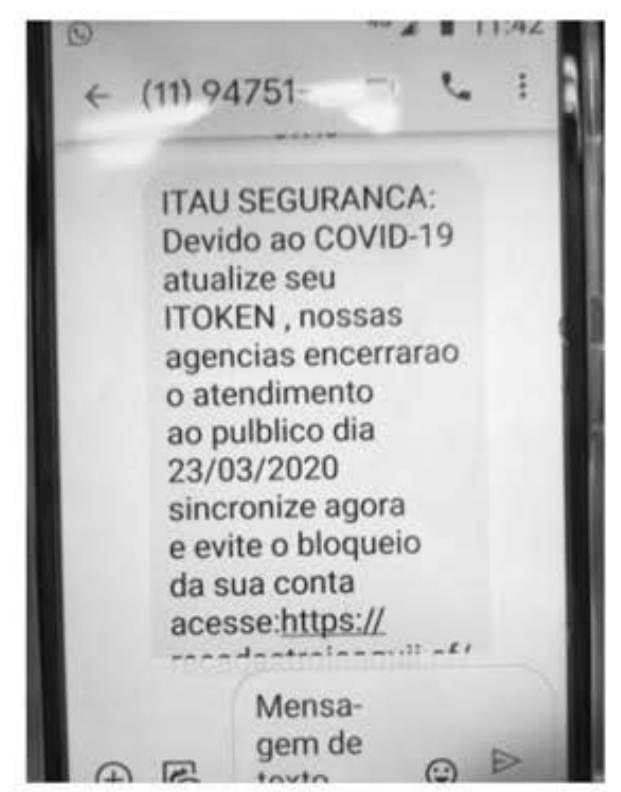

Figura 2. Notificação de golpe bancário recebida pelo Eu Fiscalizo entre 17 de março e 10 de abril.

Fonte: Post extraído do banco de dados do aplicativo Eu Fiscalizo. drogas. Martins defende que, quando uma pessoa recebe uma notícia que a agrada, são estimulados mecanismos de recompensa e prazer imediatos do cérebro. Isso a impulsiona a transmitir compulsivamente a mesma informação para que seu círculo de amizades sinta o mesmo. Explica assim o comportamento dos encaminhadores compulsivos de notícias falsas. Na visão do pesquisador, essa sensação de euforia impede o desenvolvimento do senso crítico de quem recebe fake news. É a "infantilização emocional", que faz com que poucas pessoas não se preocupem em checar a origem ou a veracidade da informação. O sentimento, explica ele, é o mesmo de quando ouvem uma fofoca. Segundo Martins, é preciso compreender que a crença em fake news é um fenômeno sociocultural que envolve diversos fatores da vida pessoal e social do ponto de vista comportamental ${ }^{38}$.

\section{Considerações finais}

Este texto apresentou a primeira etapa de uma pesquisa sobre fake news, para compreender a as-

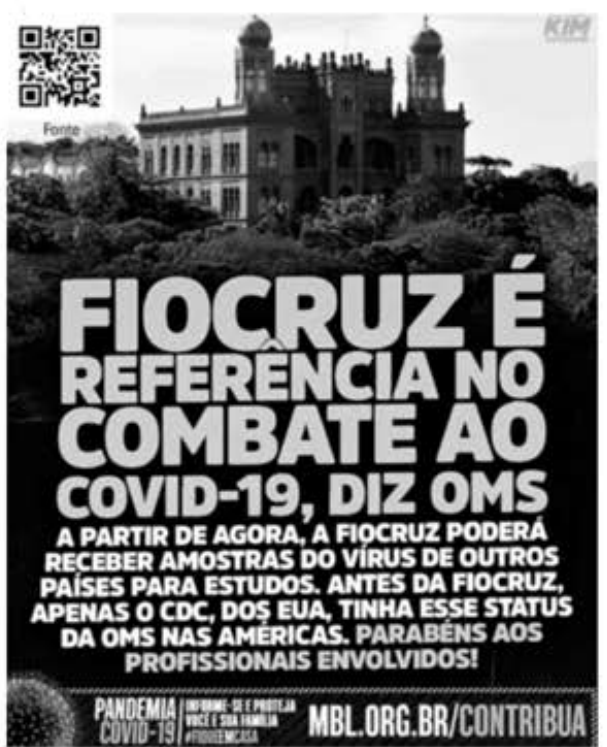

Figura 3. Notificação da falsa campanha de arrecadação recebida pelo Eu Fiscalizo entre 17 de março e 10 de abril.

Fonte: Post extraído do banco de dados do aplicativo Eu Fiscalizo. 


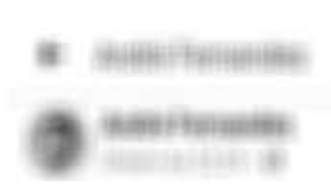

Esses săo dados oficiais do Portal de Transparência de Registro Civil. Os números se referem ao mesmo período do ano passado, ou seja, de 16/03 a 10/05 de 2019.

Com isso só temos duas conclusões: ou ano passado as vidas eram menos importantes que as desse ano, ou, estão usando essas mortes como arma política em ano de eleição.

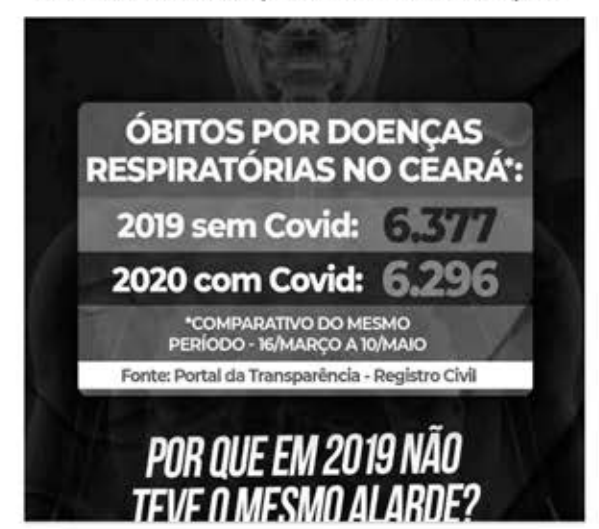

Figura 4. Notificação de distorções de dados sobre óbitos no Brasil recebida pelo Eu Fiscalizo entre 17 de março e 10 de abril.

Fonte: Post extraído do banco de dados do aplicativo Eu Fiscalizo.

censão do negacionismo à informação científica em tempos de pandemia da Covid-19 na era da pós-verdade. Em primeiro lugar, cabe ressaltar o pouco investimento da área da saúde nas tecnologias de longo alcance, baseadas na ciência da informação, ponto que foi tratado por Souza ${ }^{39}$ em recente artigo. Portanto, considera-se importante este trabalho, mais informativo que analítico que esquenta o debate sobre as fake news.

Os dados aqui levantados permitem evidenciar que o aplicativo de mensagens WhatsApp é a plataforma mais utilizada na disseminação de desinformação. A rede social Facebook ocupa o segundo lugar.

Ao analisar o fenômeno das fake news em saúde, durante a pandemia, é possível afirmar que a disseminação de notícias falsas contribui para o descrédito da ciência e das instituições globais de saúde pública, bem como enfraquece a adesão da população aos cuidados necessários de prevenção, ao lidar com a epidemia.

Cumpre lembrar, na linha de construção do descrédito institucional, que o estudo empírico que usou o aplicativo Eu fiscalizo, mostrou que $26,6 \%$ das fake news publicadas no Facebook apontam a Fiocruz como orientadora de receitas caseiras para proteção contra o novo coronavírus. E 71,4\% das mensagens falsas circuladas pelo WhatsApp citam a Fundação Oswaldo Cruz como fonte de textos com orientações de medidas de proteção caseiras para eliminar o vírus. Em resumo, o estudo revela que o nome dessa instituição é usado para legitimar a desinformação em saúde. Essa ação intencional pode contribuir para a tomada de decisões equivocadas e para promover a descrença na ciência e nas orientações oficiais.

E, como acabar com as fake news? Essa é a pergunta que instiga a mídia e a sociedade atualmente. Trata-se de uma empreitada difícil e complexa. O que se pode recomendar é que o cidadão sempre confira o conteúdo propagado vindo de supostas fontes oficiais. Paralelamente, é necessário que as instituições aumentem o nível de informações confiáveis acessíveis para a toda a população. Muitos pesquisadores que atuam no campo da comunicação ressaltam que a tentação de regular os conteúdos é uma manobra delicada, pois ela pode flertar com a censura, o que é abominável. A melhor abordagem regulatória possivelmente seja atuar diretamente no debate público, aumentando a consciência social sobre os impactos deletérios das fake news. Um esforço importante feito pela Comunidade Europeia visa a aumentar o grau de conhecimento científico na vida social. No Brasil também, apesar de toda a intempérie política conjuntural, parece que esse processo também está ocorrendo e é importante incentivá-lo.

No mesmo sentido, é fundamental que se realizem e se aprofundem pesquisas que contenham hipóteses sobre crenças e valores das pessoas que aderem mais facilmente às narrativas veiculadas nas redes. É igualmente imprescindível que se busque compreender como ocorre a mediação entre as plataformas digitais e a sociedade consumidora e compartilhadora de conteúdo.

Uma nota sobre as limitações deste artigo. O trabalho empírico consistiu na observação de um período curto de funcionamento do Eu fiscalizo. É o que foi possível fazer no momento. No entanto, considera-se importante aprofundar seu papel e contribuição e trazer a tona questões que ajudem a melhorar a interação com a popu- 
lação visando à saúde no país. Igualmente, temse consciência de que, embora este texto traga muita informação, questões centrais para análise do fenômeno das fake news não foram respondidas. As reflexões hoje existentes ainda são muito contraditórias, superficiais, erráticas e precisam ser aprofundadas, o que não se conseguiu neste trabalho. Seu papel, possivelmente, seja o de levantar questões a serem pesquisadas e debatidas no âmbito acadêmico e na arena das práticas políticas e sociais.

\section{Referências}

1. World Health Organization (WHO). WHO Director-General's opening remarks at the media briefing on COVID-19 [Internet]. 2020 [acessado 2020 Jun 12]. Disponível em: https://www.who.int/dg/speeches/detail/who-director-general-s-opening-remarks-at-themedia-briefing-on-covid-19---11-march-2020

2. Aquino EML, Silveira IH, Pescarini JM, Aquino R, Souza-Filho JA, Rocha AS, Ferreira A, Victor A, Teixeira C, Machado DB, Paixão E, Alves FJO, Pilecco F, Menezes G, Gabrielli L, Leite L, Almeida MCC, Ortelan N, Fernandes QHRF, Ortiz RJF, Palmeira RN, Pinto Junior EP, Aragão E, Souza LEPF, Barral Netto M, Teixeira MG, Barreto ML, Ichihara MY, Lima RTRS. Medidas de distanciamento social no controle da pandemia de COVID-19: potenciais impactos e desafios no Brasil. Ciên Saude Colet 2020; 25(Supl. 1):2423-2446.

3. Brasil. Ministério da Saúde (MS). Orientações para retomada com segurança [Internet]. 2020 [acessado 2020 Jul 20]. Disponível em: https://coronavirus.saude.gov.br/orientacoes-para-retomada-com-seguranca

4. G1. São Paulo registra a primeira morte pelo novo coronavírus no Brasil [Internet]. 2020 [acessado $2020 \mathrm{Jul}$ 20]. Disponível em: https://g1.globo.com/sp/sao-paulo/noticia/2020/03/17/estado-de-sp-tem-o-primeirocaso-de-morte-provocada-pelo-coronavirus.ghtml

5. El País. Mandetta apela por isolamento para evitar colapso do sistema de saúde no final de abril [Internet]. 2020 [acessado 2020 Jul 20]. Disponível em: https:// brasil.elpais.com/brasil/2020-03-20/mandetta-apela -por-isolamento-para-evitar-colapso-do-sistema-desaude-no-final-de-abril.html

\section{Colaboradores}

CP Galhardi participou da concepção, metodologia, análise estatística; interpretação dos dados e redação do artigo. NP Freire participou da concepção, delineamento, redação do artigo e discussão dos achados. MCS Minayo orientou a pesquisa, revisão crítica do conteúdo intelectual; discussão dos achados, aprovação final da versão a ser publicada. MCM Fagundes realizou o levantamento bibliográfico.
6. O Globo. Da 'gripezinha' ao 'e daí?', confira as reações de Bolsonaro enquanto aumentavam as mortes pela pandemia no Brasil [Internet]. 2020 [acessado 2020 Jul 20]. Disponível em: https://oglobo.globo.com/ brasil/da-gripezinha-ao-dai-confira-as-reacoes-de -bolsonaro-enquanto-aumentavam-as-mortes-pela -pandemia-no-brasil-24402593

7. Zarocostas J. How to fight an infodemic. Lancet 2020; 395(10225):676.

8. Fundação de Amparo à Pesquisa do Estado de São Paulo (FAPESP). Epidemia de fake news [Internet]. 2020 [acessado 2020 Jul 20]. Disponível em: https:// revistapesquisa.fapesp.br/epidemia-de-fake-news/

9. Sacramento I, Paiva R. Fake News, WhatsApp e a vacinação contra febre amarela no Brasil. Matrizes 2020; 14(1):79-106.

10. Henriques C. A dupla epidemia: febre amarela e desinformação. Rev Eletrônica Comunicação Informação Inovação Saúde 2018; 12(1):9-13.

11. Lara-Navarra P, Falciani H, Sánchez-Pérez EA, FerrerSapena A. Gerenciamento de informações em saúde e meio ambiente: em direção a um sistema automático para detecção de notícias falsas. Int J Environ Res Public Health 2020; 17:1066-1076.

12. Dicionário de Cambridge. Significado de fake news em inglês [Internet]. Cambridge Dictionaire. [acessado 2020 Jul 20]. Disponível em: https://dictionary.cambridge.org/pt/dicionario/ingles/fake-news

13. Estadão. WhatsApp confirma ação de empresas em disparo de mensagens durante eleições [Internet]. 2019 [acessado 2020 Jul 20]. Disponível em: https://politica.estadao.com.br/blogs/estadao-verifica/whatsappconfirma-acao-de-empresas-em-disparo-de-mensagens-durante-eleicoes/ 
14. Revista Piauí. Cenas de um Brexit sem fim: As consequências da pequena rebeldia britânica [Internet]. 2019 [acessado 2020 Jul 20]. Disponível em: https:// piaui.folha.uol.com.br/materia/cenas-de-um-brexitsem-fim/

15. UOL. Coronavírus faz CPI das Fake News estudar 52 quebras de sigilo à distância [Internet]. Brasília; 2020 [acessado 2020 Jul 20]. Disponível em: https://noticias.uol.com.br/politica/ultimas-noticias/2020/03/20/coronavirus-cpi-fakenews-votacao52-quebras-sigilos-whatsapp-facebook.htm

16. Weedon J, Nuland W, Stamos A. Information Operations and Facebook [Internet]. Facebook Newsroom; 2017 [acessado 2020 Jul 02]. Disponível em: https:// fbnewsroomus.files.wordpress.com/2017/04/facebook-and-information-operations-v1.pdf

17. Garcia JS. Paralogismos y sofismas del discurso político español. La falacia en un corpus de debates parlamentarios. Anuario Estudios Filológicos 2010; 33:271290.

18. Dicionário de Oxford. Definition of post-truth adjective from the Oxford Advanced Learner's Dictionary [Internet]. [acessado 2020 Jun 15]. Disponível em: https://www.oxfordlearnersdictionaries.com/us/definition/english/post-truth?q=POST-TRUTH

19. D’Ancona M. Pós-verdade: a nova guerra contra os fatos em tempos de fake news. Barueri: Faro editorial; 2018.

20. Figueira J; Santos S. As fake news, a nova ordem (des) informativa. Coimbra: University Press; 2019.

21. Barbosa M. Isso a impressa não mostra. In: Barbosa A, organizador. Pós-verdade e fake news: reflexões sobre a guerra de narrativas. Rio de Janeiro: Cobogó; 2019. p.7-17.

22. Agência Fiocruz de Notícias. Pesquisadoras da Fiocruz lançam novo aplicativo Eu Fiscalizo [Internet]. 2020 [acessado 2020 Jun 25]. Disponível em: https://agencia.fiocruz.br/pesquisadoras-da-fiocruz-lancam-novo-aplicativo-eu-fiscalizo

23. Bardin L. Análise de conteúdo. São Paulo: Almedina Brasil; 2011.

24. Krippendorff K. Content Analysis: An introduction to its methodology. Los Angeles: Sage; 2013.

25. Minayo MCS. O desafio do conhecimento. São Paulo: Editora Hucitec; 2015.

26. Igartua JJ. Métodos cuantitativos de investigación en comunicación. Barcelona: Bosch; 2006.

27. Informe ENSP. Pesquisa revela dados sobre Fake News relacionadas ao novo coronavírus [Internet]. [acessado 2020 Jul 21]. Disponível em: http://www.ensp.fiocruz. br/portal-ensp/informe/site/materia/detalhe/48662

28. AVAAZ. O Brasil está sofrendo uma infodemia de Covid-19 [Internet]. [acessado 2020 Jul 07]. Disponível em: https://avaazimages.avaaz.org/brasil_infodemia_ coronavirus.pdf

29. Coletiva.Net. Pesquisa alerta que sete a cada dez brasileiros acreditam em fake news sobre Covid-19 [Internet]. 2020 [acessado 2020 Jul 05]. Disponível em: https://coletiva.net/noticias/pesquisa-alerta-que-sete -em-cada-dez-brasileiros-acreditam-em-fake-newssobre-covid-19,358082.jhtml
30. Revista VEJA. Casos de intoxicação por desinfetantes crescem em NY após sugestão de Trump [Internet]. 2020 [acessado 2020 Jul 22]. Disponível em: https:// veja.abril.com.br/mundo/casos-de-intoxicacao-pordesinfetante-crescem-em-ny-apos-sugestao-detrump/

31. Delmazo C, Valente CLJ. Fake news nas redes sociais online: propagação e reações à desinformação em busca de cliques. Média Jornalismo 2018; 1:155-169.

32. Agência LUPA. Na pandemia, criminosos usam falsas ofertas e beneficios para aplicar golpes [Internet]. 2020 [acessado 2020 Jul 10]. Disponível em: https://piaui. folha.uol.com.br/lupa/2020/07/21/coronaverificadogolpes-pandemia/

33. Empresa Kaspersky. $62 \%$ dos brasileiros não sabem reconhecer uma notícia falsa [Internet]. 2020 [acessado 2020 Jul 18]. Disponível em: https://www.kaspersky. com.br/about/press-releases/2020_62-dos-brasileiros-nao-sabem-reconhecer-uma-noticia-falsa

34. Informe ENSP. Pesquisa revela dados sobre fake news relacionadas ao novo coronavírus [Internet]. [acessado 2020 Jul 21]. Disponível em: http://www.ensp.fiocruz. br/portal-ensp/informe/site/materia/detalhe/48662

35. NUJOC Checagem. Perdeu a linha: afirmações do deputado estadual (PSL-CE), André Fernandes, sobre as mortes por COVID 19 são falsas [Internet]. 2020 [acessado 2020 Jul 02]. Disponível em: https://nujocchecagem.wordpress.com/2020/06/25/perdeu-a-linha-afirmacoes-do-deputado-estadual-psl-ce-andrefernandes-sobre-as-mortes-por-covid-19-sao-falsas/

36. Vosoughi S, Roy D, Aralet S. The spread of true and false news online. Science 2018; 359(6380):1146-1151.

37. Van Bavel JJ, Pereira A. The Partisan Brain: An Identity-Based Model of Political Belief. Trends Cognitive Sci 2018; 22(3):213-224

38. BBC Brasil. 'É como usar drogas': por que as pessoas acreditam e compartilham notícias falsas? [Internet]. São Paulo; 2018 [acessado 2020 Jul 02]. Disponível em: https://www.bbc.com/portuguese/brasil-45767478

39. Souza OD. A pandemia de COVID-19 para além das Ciências da Saúde: reflexões sobre sua determinação social. Cien Saude Colet 2020; 25(Supl. 1):2469-2477.

Artigo apresentado em 13/08/2020

Aprovado em 15/08/2020

Versão final apresentada em 17/08/2020 